\title{
Study on College Students' Innovation Entrepreneurship Evaluation System Based on SWOT
}

\author{
Bin $\mathrm{Ma}^{1}$, Jiajing Chen ${ }^{1, *}$, Xufang Zhang ${ }^{2}$ \\ ${ }^{1}$ School of Information Engineering, North China University of Water Resources and Electric Power, Zhengzhou, Henan \\ 450046, China \\ ${ }^{2}$ School of Materials, North China University of Water Resources and Electric Power, Zhengzhou, Henan 450046, China \\ *Corresponding author. Email: $1415931869 @$ qq.com
}

\begin{abstract}
Cultivating innovative talents is the core of social development, and college students are undoubtedly the most popular objects, but how to measure their innovation and entrepreneurship has become a key issue. This article focuses on how to evaluate the ability of dual-innovation, using the SWOT method to analyze the evaluation system of computer innovation in colleges and universities, and conduct a comprehensive, systematic and accurate study of the current evaluation system. This leads to the main internal strengths, weaknesses, and external opportunities and threats that are closely related to the current evaluation system. Furthermore, in view of the limitations of the current system, a variety of evaluation methods have been proposed. Construct evaluation models from multiple aspects and methods, and establish countermeasures such as evaluation feedback mechanisms, so as to provide new ideas for the cultivation of a new generation of high-quality talents with dual innovative capabilities.

Keywords: Innovation and entrepreneurship, evaluation system, SWOT
\end{abstract}

\section{INTRODUCTION}

In order to cope with the gradual socialization and capitalization of information, technology, knowledge and other elements, Premier $\mathrm{Li}$ Keqiang proposed in the government work report to provide all-round innovation and entrepreneurship services, encourage all parties in the society to open up innovation resources, and create a new pattern of innovation and entrepreneurship. In recent years, colleges and universities across the country have set off an upsurge of innovation and entrepreneurship education, and have made many efforts to cultivate and improve college students' entrepreneurial ability, such as college employment and entrepreneurship education, college student employment and entrepreneurship, and evaluation of college students' innovation ability. Among them, the construction of the evaluation system of college students' innovation and entrepreneurship ability has become one of the key issues in talent cultivation research.

At present, foreign scholars pay more attention to the psychological characteristics and personality characteristics of entrepreneurs. As William D. Bygrave puts forward, good entrepreneurs need to have the qualities of sharing, ideals, and money. Three-sided model proposed by Sternberg. Gideon D. Markman proposed a personal entrepreneurship fit model. Lowingfield proposed Multifactor perspective of creativity based on comprehensive mental ability. Domestic scholar De-gang SUN [1] analyzes the innovative and entrepreneurial qualities of college students from personal, entrepreneurial, innovative and psychological aspects. Jian-feng HU [2] constructed an evaluation index system based on innovation and entrepreneurship, comprehensive output and professional ability output. Xiao-dong ZOU [3] proposed an evaluation index system for university entrepreneurship based on patents, technology transfer, school-run industries, and industrial funding. In the research process, Qin-ling LIU [4] used the literature survey method to analyze the entrepreneurial research literature published by important academic journals at home and abroad. The 10 most frequent indicators were directly formed into a first-level indicator for the evaluation of university students' innovative entrepreneurship, but the method lacks pertinence. In terms of evaluation methods, scholars often use methods such as analytic hierarchy process, multi-dimensional model method, grey fuzzy comprehensive evaluation method, entropy weight method and so on. [5-8]

Through the investigation and literature analysis of enterprise talents [9-11], it is found that students' dual-innovation ability comes from internal and external factors. Among them, internal factors include professional skills and comprehensive qualities, which play a decisive role. From the perspective of talent training, higher education is a process of continuously stimulating, consolidating, strengthening and promoting these inherent factors of students. As far as the professional curriculum system is concerned, the cultivation of professional skills is mainly focused on teaching links such as basic theory, professional foundation, professional core, and in-class experiments; and the cultivation of comprehensive quality is mainly in ideological and political courses, foreign 
language courses, and practical links and literature and art courses. At present, the evaluation of student learning status in various courses in colleges and universities is mainly based on student's output results (including test paper results and various documents). Although the evaluation of the dual-innovation ability is also accompanied, it is not targeted. Based on this, this article conducts SWOT analysis and countermeasures on the current dual-innovation ability evaluation process and method of computer majors in universities.

\section{SWOT ANALYSIS}

\subsection{Strengths}

From the perspective of innovation and entrepreneurship, the necessary professional accumulation and professional practical ability are an important factor for success. The current evaluation methods of teaching effects focus on the evaluation of professional knowledge system, structure, and mastery. The evaluation methods include two types of evaluation methods based on scores (such as test papers) and process-based evaluation methods. The first type of evaluation method has good objectivity. It can analyze the professional basic situation and professional skill status of students from the distribution of the scores obtained by each student and the composition of the results. This type of evaluation promotes the accumulation of students' professional skills and practical abilities, thereby forming a professional skill advantage in the process of entrepreneurship and innovation. The second type of evaluation method is based on classroom participation, organizational activities, practical processes, and writing. As a basis for judging the teacher's subjective perspective, the practice, organization, skills, and communication of each student in the practice link and teaching process and other capabilities. This type of evaluation method mainly reflects the cultivation of students' engineering management, teamwork, social communication and expression skills in their professional field. This provides students with a good quality advantage by entering the society smoothly and seeking appropriate work and business expressions. In addition, in terms of evaluation content, the evaluation of higher education focuses more on assessing students' ability from an overall perspective. The distribution of weights specifically quantifies the major and difficult points of professional courses, and systematically evaluates from the levels of understanding, familiarity, understanding, and mastery. For students, it is conducive to students' innovative and entrepreneurial spirit, gaining wider development space and showing their ability to work.

\subsection{Weaknesses}

Of course, "dual-innovation" is innovation and entrepreneurship, and many ideas cannot be followed. In the field of information technology, new technologies, new methods, and new ideas emerge endlessly. It can be said that innovation is happening all the time, and innovation is everywhere. And by tracking the graduates' working ability and innovation ability, it can be found that although the current talent evaluation program is more recognized by the society, most employers in the more than 20 companies surveyed review "the cultivation effect is good, but the innovation ability is slightly insufficient". Investigating the reason, it is not difficult to find that it is mainly caused by the baton of "what exams take, what students learn". For the students themselves, due to the pursuit of good grades, students learn more about the content of the books to be assessed, but pay less attention to the knowledge outside the books, which makes students find insufficient awareness of social, production, and life issues; in terms of assessment questions, because the roll assessment must take care of most students' learning, the scope of teachers' questions is limited by the assessment difficulty and assessment time, which makes the assessment of knowledge utilization ability simpler, and it is difficult to assess Learning ability, self-improvement ability after leaving school, team communication and cooperation ability are reflected in the key factors of innovation and entrepreneurship; from the assessment results, the written scores reflect more the students' familiarity with known knowledge rather than Assess students' ability to discover and solve new problems; from the teacher's perspective, the teachers lack of understanding of "dual-innovation", less social practice, new things, new technologies, and new attitudes will also lead to students' "dual-innovation " lack of consciousness.

\subsection{Opportunity}

In recent years, with the emergence of a large number of new technologies such as computer network technology, big data technology, artificial intelligence technology, especially the development of engineering education certification, the training of computer talents in universities has undergone new changes compared with the past ten years. First of all, solid theoretical knowledge and a strong professional foundation provide students with a basic guarantee to propose new methods and complete entrepreneurship. The advent of the Internet + era has provided unprecedented opportunities for computer major students' employment and entrepreneurship. Secondly, the introduction of the $\mathrm{OBE}$ concept adds new ideas to teaching evaluation. The OBE concept serves as the basic idea for teaching reform. It guides the evaluation of students from knowledge assessment to ability assessment, closely links practice links, ability training and talent goals, and connects professional knowledge transformed into the power of innovation and entrepreneurship to provide 
intellectual support for social development. Finally, the use of new technologies, new methods, new media and other methods makes the evaluation process more flexible. Among them, big data analysis technology, artificial intelligence judgment technology, and VR virtual simulation experiment platform for student learning process make student evaluation more comprehensive, more reasonable, and more operable, and the use of new technologies provides a brand new platform for the cultivation of the spirit of innovation and the improvement of entrepreneurial capabilities, which promote each other.

\subsection{Threats}

Threats and opportunities coexist. First of all, for the content of the evaluation of innovation and entrepreneurship, some content is difficult to reflect in scrolls, and some content varies from person to person. This requires teachers to spend more time preparing materials and more detailed observations, and establish more detailed evaluation principles. In the case of measuring the teacher's work with the same workload, the burden on teachers will increase significantly. Secondly, during the introduction of new technologies, how to enable teachers to intensify their studies on the basis of completing their work and to keep pace with the technology is a big challenge for the faster updating of computer technology. Thirdly, for the assessment of the practice link, "dual-innovation" must be reflected in the practice process and the final results. Can't design experiments based solely on professional knowledge in books. This makes it more difficult for teachers to arrange practical content and conduct assessments. In particular, the learning habits of students are inertia. After experiencing education in elementary and junior high schools, it is an important challenge to be able to adapt to the assessment of the "dual-innovation" ability as soon as possible. Finally, teachers and schools have limited entrepreneurial ability. How to cultivate students' entrepreneurial spirit and stimulate students' entrepreneurial ability. On the basis of taking into account learning, improving the innovative and entrepreneurial system of classroom and practical teaching is also a challenge.

To sum up, the current computer professional training program has advantages and disadvantages, and the talent training process has opportunities and challenges. Based on this, this article has designed a new set of teaching models in order to solve existing problems and difficulties, and put forward some ideas for the "dual-innovation" type talent training work.

\section{COUNTERMEASURES}

\subsection{Extended evaluation content}

Computer majors have higher requirements for students' practical ability, problem analysis ability, and engineering literacy, and it is more suitable to incorporate innovation and entrepreneurial factors in teaching evaluation content.

(1) Teachers should attach importance to the education and evaluation of students' ideological quality, emphasize engineering ethics, and organically combine evaluation and education. This not only strengthens the education of students' professional theories, but also cultivates the spirit of advancing with the times and being creative.

(2) Pay attention to the extension of classroom teaching content, and jointly design practical content and custom experimental projects with enterprises. To enable students to participate directly or indirectly in society, enterprises, employers and scientific research projects, so as to combine corporate culture and technical needs, students' actual needs, and career development planning.

(3) Through research, design, development and other methods, guide students to comprehensively consider technical, social, cultural, economic and other issues to solve an actual engineering problem. The analysis and discussion process is used as the evaluation content, which effectively stimulates students' enthusiasm for participating in the teaching process and academic enthusiasm for discussion, and improves students' study and research capabilities and comprehensive quality.

\subsection{Diversified evaluation methods}

\subsubsection{Evaluation based on multi-party evaluation mechanism}

For the assessment of the course and practice scores, a process-oriented assessment and assessment method is used instead of the original achievement assessment and attendance assessment method. According to the classroom teaching process and experimental organization, students, groups, and teachers evaluate the learning process and practice results separately, not only from the degree of completion, functionality, and economic value of student results, but also from social welfare, Innovativeness and engineering ethics make comprehensive judgments on results. At the same time, industry experts and company project managers are invited to organize teaching, jointly analyze the operating process, reports, documents and other materials generated by each project team in the teaching process, and analyze classroom teaching results according to the performance of each student. On the one hand, it is more targeted to analyze the omissions of the teacher's lectures and make suggestions and improve ideas. On the other hand, enterprises and students directly interface with 
each other, providing a broader information platform for student employment.

\subsubsection{Construction of multi-factor evaluation model for evaluation}

According to the characteristics of "dual-innovation", we will determine the influencing factors around soft indicators such as engineering practice ability, professional literacy, industry background analysis, and social environment impact, and construct a multi-factor evaluation model so that the performance can better reflect the students' innovative ideas and innovation. So as to guide and encourage students to be more innovative and creative in the teaching process.

\subsubsection{Evaluation based on competition}

At present, there are many types of computer competitions, such as programming, network skills, network security, and big data. These competitions reflect to a certain extent new technologies, new ideas, and professional comprehensive application capabilities. Therefore, a competition reward system and credit replacement system can be established to encourage students to participate in various discipline competitions. In the evaluation of students, competition results are introduced to test the effectiveness of courses and professional learning, so as to stimulate students' interest in learning, cultivate students' innovative spirit, improve students' professional skills, and promote student employment and entrepreneurship.

\subsection{Establish an evaluation feedback mechanism}

In order to promote the good operation of the evaluation mechanism and continuously improve the evaluation methods to continuously improve the quality of teaching, an effective evaluation feedback mechanism needs to be established, as shown in Figure 1. It can start with the evaluation of knowledge system, evaluation of practical problem-solving ability and evaluation of ethics and ethics, and collect graduate tracking feedback, social evaluation feedback, teaching evaluation feedback, and student teaching evaluation. Based on the discussion of the problems existing in the teaching evaluation, feedback was formed and fed back to the major and the person in charge of each course, laying a foundation for the further improvement of the evaluation mechanism.

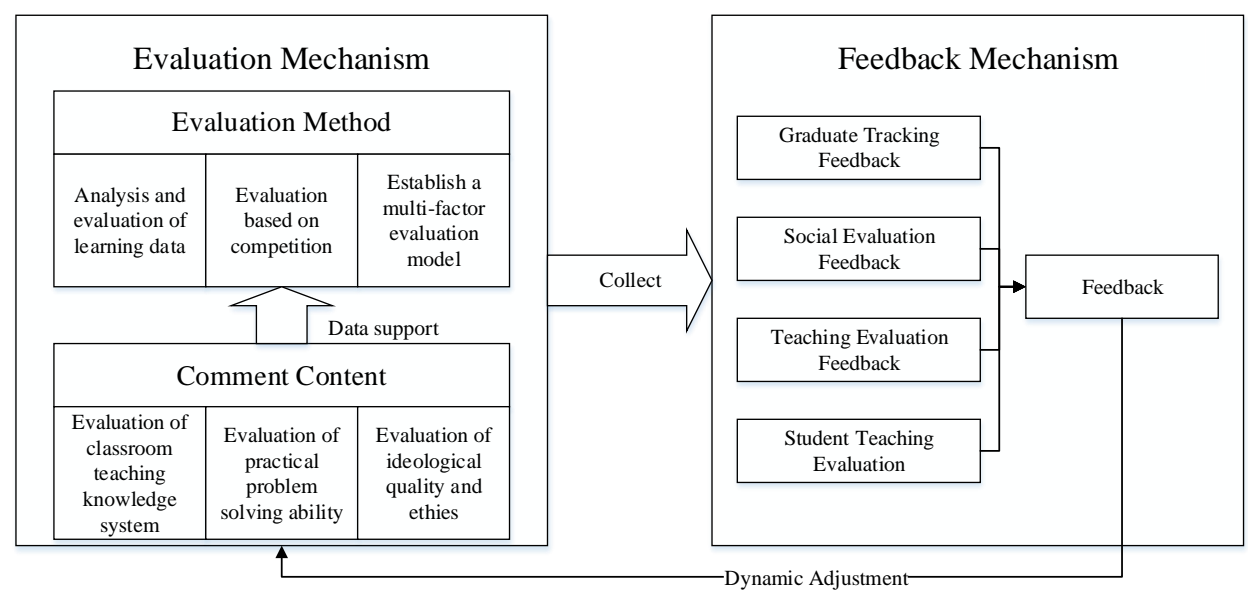

Figure 1 Evaluation feedback mechanism

\section{CONCLUSION}

Encouraging "dual-innovation" is an important way to effectively respond to internal and external pressures. Assessing "dual-innovation" is a way to quantify the ability of talents to create double innovations. After analyzing the problems existing in the current evaluation mechanism, this article proposes a new evaluation method, which is to expand the evaluation content, diversify the evaluation methods, and establish an evaluation feedback mechanism to improve the level of university students' dual innovation ability and produce high-quality innovative entrepreneurial talents.

\section{ACKNOWLEDGMENTS}

[1] The Employment and Entrepreneurship Project of Henan Province's Colleges and Universities, "Research on the Evaluation System for the Innovation and Entrepreneurship Ability of University Students in the New Era" (JYB2019007);

[2] North China University of Water Resources and Hydropower, Teaching Reform Project, "3D 
Computer Architecture for Distance Teaching Construction of simulation digital resource library";

[3] North China University of Water Resources and Hydropower, Innovation and Entrepreneurship and Employment Project" Research on University Students' Innovation and Entrepreneurship Evaluation System ".

\section{REFERENCES}

[1] De-gang Sun, Xin-tong Wu. An empirical study on the quality of innovation and entrepreneurship of engineering majors $[\mathrm{J}]$. Higher Education Exploration, 2016 (5): 124-128.

[2] Jian-feng Hu, Yong Jiang. Research on the Course System Construction of Innovation and Entrepreneurship Education in Colleges and Universities [J]. Innovation and Entrepreneurship Education, 2016, 7 (4): 107-109.

[3] Xiao-dong Zou, Han-cong Chen. Entrepreneurial University: Conceptual Connotation, Organizational Characteristics and Practical Approaches [J]. Research in Higher Engineering Education, 2011 (3): 54-59.

[4] Qin-ling Liu. Construction of Evaluation Index System of Innovative Entrepreneurship Capability-Based on the Investigation of First Entrepreneurship Cases of Chinese College Students [J]. Research on Science and Technology Management, 2013 (24): 65-69.

[5] Jin-bang Zhang, Shu-jing Cheng, Jun-sheng Zhang. Construction of Evaluation Index for College Students' Innovation and Entrepreneurship Based on AHP Model [J]. Journal of Liaoning Institute of Science and Technology, 2017, 19 (3): 29-30.

[6] Ting Wu, Yi-fan Zeng, Li-ji Zeng. AHP-based Evaluation of University Students' Innovation and Entrepreneurship Ability [J]. Journal of Jiangxi Youth Vocational College, 2015, 25 (6): 21-24.

[7]Shu-yu Qi, Yao-yao Fang. Construction and Design of Evaluation Index System for Innovation and Entrepreneurship of Engineering Students [J]. Science and Technology Management Research, 2017 (24): 68-74.

[8]Chen Luo, Wei Wei. Important Links in Entrepreneurship Education: Establishing an
Entrepreneurship Evaluation System [J]. Continuing Education, 2013 (7): 16-18.

[9] Xian Zhu, Lin-lin CHEN, Ling XIE, etc. Research on the Evaluation System of Innovation and Entrepreneurship Education [J]. Comparative Study on Cultural Innovation, 2018 (31): 87-89.

[10] Li-yi Ma, Qin HE, Qiu-yan TAO. A Review of the Research on the Evaluation Index System of College Students' Innovation and Entrepreneurship Ability [J]. Science \& Technology Economics Guide, 2017 (32): 144-145, 148.

[11] Rui-jie Xie. Research on practical teaching system with the goal of cultivating innovation and entrepreneurship [J]. Laboratory Science, 2016, 19 (1): 174-1. 